\title{
Short-Term Dynamics Reveals Seasonality in a Subtropical Heliconius Butterfly
}

\author{
Thadeu Sobral-Souza, ${ }^{1}$ Ronaldo Bastos Francini, ${ }^{2}$ \\ Murilo Guimarães, ${ }^{3}$ and Woodruff Withman Benson ${ }^{4}$ \\ ${ }^{1}$ Programa de Pós-Graduação em Ecologia, Instituto de Biologia, Universidade Estadual de Campinas, P.O. Box 6109, \\ 13083-970 Campinas, SP, Brazil \\ ${ }^{2}$ Laboratório de Biologia da Conservação, Universidade Católica de Santos, Campus D. Idílio José Soares, 11015-200 Santos, SP, Brazil \\ ${ }^{3}$ Departamento de Zoologia, Instituto de Biociências, Universidade Federal do Rio Grande do Sul, 91501-970 Porto Alegre, RS, Brazil \\ ${ }^{4}$ Departamento de Biologia Animal, Instituto de Biologia, Universidade Estadual de Campinas, P.O. Box 6109, \\ 13083-970 Campinas, SP, Brazil
}

Correspondence should be addressed to Thadeu Sobral-Souza; thadeusobral@gmail.com

Received 12 August 2015; Accepted 5 November 2015

Academic Editor: Fedai Erler

Copyright (C) 2015 Thadeu Sobral-Souza et al. This is an open access article distributed under the Creative Commons Attribution License, which permits unrestricted use, distribution, and reproduction in any medium, provided the original work is properly cited.

Although tropical insect populations are generally regarded as constant and stable over time, some of these tropical populations, including butterflies, may fluctuate according to precipitation and temperature variation, specialized feeding patterns, and densitydependent factors. Heliconiini butterfly populations are generally regarded as stable over time because of the presence of hostplants and absence of diapause. However, peaks of abundance occur in subtropical Heliconius populations, and opposite trends concerning stability are found in the literature. Here we further investigate the dynamics of subtropical Heliconius butterflies by assessing a population of the species Heliconius sara apseudes from southeastern Brazil. We estimated individual apparent survival probability and population growth rate while accounting for the imperfect detectability of individuals using mark-recapture models to evaluate the population dynamics. Adult males presented slightly higher weekly survival estimates than females. Contrary to the common pattern described in the literature for Heliconius populations we observed a rapid decline on the adult population by the end of the mating season, possibly leading to local extinction. We discuss the potential drivers for such dynamics.

\section{Introduction}

The first studies on insect population dynamics were performed to better understand agricultural pests and found that resource availability, parasitoids, and climatic factors were among the most important factors affecting population dynamics [1]. In the tropics insect populations are generally regarded as constant and stable over time mainly because of climate stability [2]. However, changes in local precipitation and temperature may cause tropical insect populations to oscillate mostly because of highly specialized feeding habits, such as those observed for temperate populations, and density-dependent factors [3-5].

Tropical populations of butterflies are also constant over time, where the climatic stability does not directly affect resource availability and density-dependent processes [6-9].
Typically, such populations are regulated by parasitoids, pathogens, and visually oriented predators, besides the difficulty of finding oviposition sites [10-12].

Heliconiini butterflies are generally distributed in small populations and present high longevity [8]. The presence of host-plants year-round and the absence of diapause guaranty reproduction throughout the year, with overlapping generations $[6,8,13]$. Populations of the genus Heliconius are often heterogeneous in space, sometimes positively correlating with environmental features, such as riverbanks, floodplains, forests, and disturbed areas. Individuals are generally solitary during the day locating resources and crossing paths daily to feed on the same flowers [14].

Despite the typical constancy over time in Heliconius populations, Fleming et al. (2005) found population peaks 
of abundance in the late dry and early wet season for $H$. charithonia from a subtropical site in Florida, USA, where fluctuations in this population corresponded to biomass of food plants consumed by larvae. Opposing the results of Fleming et al. (2005), data on Heliconius populations from the subtropical region of Southern Hemisphere showed constancy and stability over time [13].

Considering the contrasting evidence found for different subtropical Heliconius populations, we surveyed another subtropical Heliconius species from the Southern Hemisphere to compare population dynamics. We specifically tested the hypothesis of stability suggested for subtropical Southern Hemisphere Heliconius, by providing estimates of individual survival and recapture probabilities, as well as population growth rates for Heliconius sara apseudes.

\section{Materials and Methods}

2.1. Study Site. Our study was conducted in the Quilombo River Valley, southeast Brazil (coordinates $23^{\circ} 51^{\prime} 35^{\prime \prime} \mathrm{S}-$ $46^{\circ} 21^{\prime} 01^{\prime \prime} \mathrm{W}$ and $\left.23^{\circ} 49^{\prime} 18^{\prime \prime} \mathrm{S}-46^{\circ} 18^{\prime} 37^{\prime \prime} \mathrm{W}\right)$. The study area is a road with $8.6 \mathrm{~km}$ that encompasses a large forested area, within the Atlantic Forest domain, but highly modified by human activities with mosaics of banana and manioc plantations in small farms.

According to Köppen (updated by [15]) this region is embedded in tropical rain climate and shows two distinct periods in this region, warm/wet (spring-summer) and cold/dry (autumn-winter). The annual mean temperature is $22.0^{\circ} \mathrm{C}$ and the annual mean total rainfall is $2541 \mathrm{~mm}$, heavily concentrated in the wet season.

2.2. Study Species. Heliconius sara is distributed throughout the neotropical region, from southern Mexico to southern Brazil [16-18]. Currently, there are 10 recognized subspecies of $H$. sara, which occur in northwest South and Central America. The only subspecies distributed in the Brazilian Atlantic Forest is $H$. s. apseudes [16, 19-21]. Females of all $H$. sara subspecies lay from 15 to 40 eggs on Passifloraceae leaves $[19,22]$. The larvae feed gregariously and pupae also aggregate [8].

2.3. Sampling Protocol. We sampled the adults of the target population for 12 months during 2009 on a weekly basis (one to two times per week), using visual cues and captured them using an entomological net. On each capture, we recorded sex of the individuals and marked them using an alphanumeric code with a black permanent ink marker on the right forewing. After marking, we released the individuals in the same site they were captured.

2.4. Statistical Analysis. We used the Pradel model to obtain maximum likelihood parameter estimates [23]. The parameterization of the Pradel model used provides estimates of apparent survival probability $(\varphi)$, which is a combination of true survival and site fidelity, recapture probability $(p)$, and the finite rate of population change $(\lambda)$, where $\lambda$ shows the rate of change through successive samples $\left(N_{t+1} / N_{t}\right)$ providing information on population stability $(\lambda=1)$, increase $(\lambda>1)$ or decrease $(\lambda<1)$. Model assumptions include a nonzero probability of recapturing all individuals through the study period, no trap response by the individuals, and most importantly, the study area must remain the same size; otherwise estimates of $\lambda$ may be biased [23, 24]. We present weekly estimates of the parameters of interest adjusting for irregular time intervals when necessary.

We kept a simple parameterization because we anticipated poor support for complex models due to our limited data set. Therefore, we built representing hypotheses about the additive effect of the covariates on the parameters, constraining each parameter to be a logit-linear function of individual and/or temporal covariates. We modeled survival as a function of sex (sex) because we suspected activity differences between adult males and females, and also as a constant parameter denoted by a period (.). Recapture probability was modeled as an additive function of maximum temperature (temp) and effort (effort) because sampling effort varied over weeks, and sex. Population growth was modeled as a function of time $(t)$, and also as a function of sex to check for different patterns of decline in adult males and females.

We selected and ranked models using the Akaike Information Criterion [25] adjusted for small sample sizes (AICc , Burnham and Anderson, 2002). We then model-averaged the parameters in order to include uncertainty in model selection [26] and reported parameter estimates with the 95\% unconditional variance confidence intervals. All routines were performed in Program MARK [27].

\section{Results and Discussion}

3.1. Results. We marked 378 males and 120 females and recaptured $106(28.04 \%)$ and $32(26.67 \%)$ at least once, respectively. The adults were found from late April (dry season) to early October (early wet season). No adult butterfly was detected before April and after October, and we present estimates for the 14-week period only.

Sex correlated with apparent survival in our best candidate models. Effort, temperature, and sex had similar impacts on recapture probability, and the additive effect of sex and time was important for the population change ( $\lambda$; Table 1$)$. Weekly apparent survival estimates differed between sexes $\left(\beta_{\text {sex }}=0.50\right.$, CI $0.03-0.98$, top model, Table 1$)$. Males $(0.66$, CI $0.57-0.73)$ presented higher survival estimates than females (0.57, CI 0.43-0.70).

Estimates of weekly recapture probability varied from 0.15 to 0.20 , and recapture was mostly constant over the study (Figure 1). Although sampling effort and maximum temperature had slightly positive effects on recapture probability, no significant influence was observed $\left(\beta_{\text {effort }}=0.27\right.$, CI $-0.25-$ 0.80 and $\left.\beta_{\text {temp }}=0.06, \mathrm{CI}-0.06-0.18\right)$. The same occurred with sex, where females presented a slightly higher recapture probability, but not statistically different from males $\left(\beta_{\text {sex }}=\right.$ 0.36 , CI $-0.25-0.98$ ).

Although models with sex ranked higher for the finite population growth rate, males and females presented almost the same pattern of growth, with males having slightly higher rate $\left(\beta_{\text {sex }}=0.06, \mathrm{CI} 0.007-0.11\right.$; Figure 2$)$. The population 
TABLE 1: Model selection results for apparent survival probability $(\varphi)$, recapture probability $(p)$, and the finite growth rate $(\lambda)$. AIC $c=$ Akaike's information criteria with small sample size correction, $\Delta \mathrm{AIC} c=$ difference between top model and the current model, $w_{i}=\mathrm{AIC} c$ weights, $k$ $=$ number of parameters, deviance $=$ difference of the current model and the saturated model. For covariate notation, see text.

\begin{tabular}{|c|c|c|c|c|c|}
\hline Model & $\mathrm{AIC} c$ & $\triangle \mathrm{AICc}$ & $w_{i}$ & $k$ & Deviance \\
\hline$\varphi(\operatorname{sex}) p$ (effort) $\lambda(\operatorname{sex}+t)$ & 2324.96 & 0.00 & 0.17 & 43 & 2229.60 \\
\hline$\varphi(\operatorname{sex}) p($ temp $) \lambda(\operatorname{sex}+t)$ & 2325.11 & 0.15 & 0.16 & 43 & 2229.74 \\
\hline$\varphi(\operatorname{sex}) p(\operatorname{sex}) \lambda(\operatorname{sex}+t)$ & 2325.68 & 0.71 & 0.12 & 43 & 2230.31 \\
\hline$\varphi(\cdot) p(\operatorname{sex}) \lambda(\operatorname{sex}+t)$ & 2326.72 & 1.75 & 0.07 & 42 & 2233.80 \\
\hline$\varphi(\cdot) p$ (effort) $\lambda(\mathrm{sex}+t)$ & 2326.91 & 1.95 & 0.06 & 42 & 2233.99 \\
\hline$\varphi($ sex $) p$ (effort) $\lambda(t)$ & 2327.07 & 2.10 & 0.06 & 42 & 2234.15 \\
\hline$\varphi($ sex $) p($ temp $) \lambda(t)$ & 2326.15 & 2.19 & 0.06 & 42 & 2234.23 \\
\hline$\varphi(\cdot) p$ (effort) $\lambda(t)$ & 2326.20 & 2.23 & 0.06 & 41 & 2236.71 \\
\hline$\varphi(\cdot) p($ temp $) \lambda(\operatorname{sex}+t)$ & 2327.51 & 2.55 & 0.05 & 42 & 2234.59 \\
\hline$\varphi(\cdot) p(\operatorname{sex}) \lambda(t)$ & 2327.52 & 2.56 & 0.05 & 41 & 2237.04 \\
\hline$\varphi(\cdot) p($ temp $) \lambda(t)$ & 2327.69 & 2.73 & 0.04 & 41 & 2233.21 \\
\hline$\varphi(\operatorname{sex}) p(\operatorname{sex}) \lambda(t)$ & 2327.92 & 2.96 & 0.04 & 42 & 2225.00 \\
\hline$\varphi(\operatorname{sex}) p(\operatorname{sex}+$ temp + effort $) \lambda(\operatorname{sex}+t)$ & 2329.56 & 4.59 & 0.02 & 45 & 2229.26 \\
\hline$\varphi(\cdot) p(\mathrm{sex}+$ temp + effort $) \lambda(\mathrm{sex}+t)$ & 2330.16 & 5.19 & 0.01 & 44 & 2232.33 \\
\hline$\varphi(\cdot) p($ sex + temp + effort $) \lambda(t)$ & 2330.80 & 5.83 & 0.01 & 43 & 2235.43 \\
\hline$\varphi($ sex $) p($ sex + temp + effort $) \lambda(t)$ & 2331.73 & 6.76 & 0.01 & 44 & 2233.90 \\
\hline
\end{tabular}

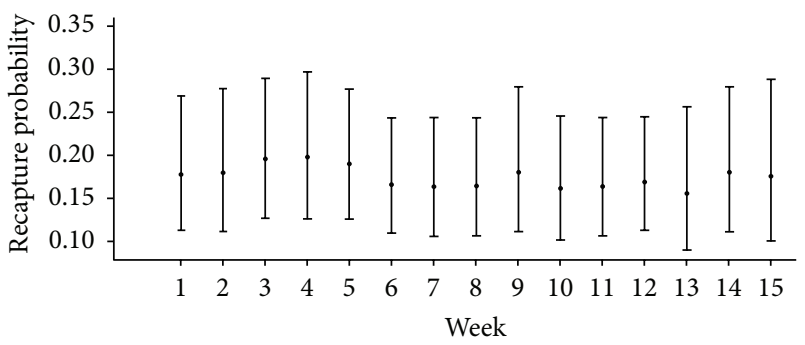

FIGURE 1: Model averaged weekly recapture probability for H. sara apseudes adults during the study period where individuals were active.

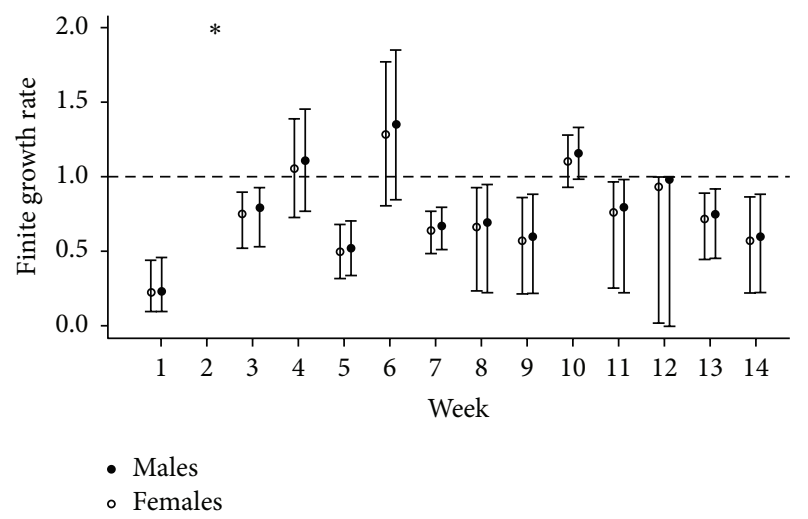

Figure 2: Finite growth rate of adult males and females $H$. sara apseudes during the period where the population was active (15 weeks). The grey dotted line represents a stable population (lambda $=1$ ). The asterisks on interval 2 indicate the abrupt increase (see text) that we chose not to plot in order to avoid distortions of values close to 1 . Estimates and $95 \%$ confidence intervals are shown. presented an abrupt increase in interval 2 (late April), where a high growth rate was detected increasing the size of the population by six times, for males $(\lambda=12.30$, CI 3.60-21.4) and for females $(\lambda=12.02$, CI 3.65-20.40). This was the only statistically significant increase in the population, since the lower boundary of the confidence interval was higher than 1 . Most of the remaining periods were characterized by declines and also some stable periods (where confidence intervals included 1; Figure 2).

3.2. Discussion. Our data demonstrates that males have a slightly higher probability of apparent survival than females. Ehrlich et al. 1984 [28] found a significantly greater number of males than females in a population of Euphydryas editha (Nymphalidae), relating this trend to either a possible female dispersion or a higher female mortality than males. It would be challenging to isolate dispersion from differential survival if detection probability is not considered during the sampling protocol. By accounting for the imperfect detectability of the individuals, we were able to split survival probability that was slightly higher for males, from the detection process of males and females, which was not different between sexes. If female dispersion was effective we would expect a lower female detection probability, which was not the case. The higher female mortality may be linked to oviposition sites, since the Heliconius host-plant, Passifloraceae, is found within the forest where more predators are present, including birds, small mammals, and spiders [10, 11].

Our results suggest seasonality in the adult population with a single substantial input of individuals in the early dry season (late April). No other significant input was found in the population despite the considerable uncertainty around the estimates (Figure 2). In Heliconius sara, eggs, larvae, 
and pupae are gregarious $[8,22]$ and emerge almost at the same time, because the development time is similar for the individuals. The only difference in this species is that males fly before females and compete for mating sites, since pupal mating is described for this species [29]. Although male population presented a slightly higher growth rate than female population, no biological difference was observed since the estimate for the intercept was close to zero, meaning that losses occur for both males and females, showing the total decline for the population.

We observed a gradual reduction in the number of males and females in the population, especially in the last time intervals, until individuals were no longer detected in the onset of the wet season (October). Although the current available information for tropical populations of Heliconius regards such group as having constancy and overlapping generations over time $[6,8]$ recent evidence on population dynamics of other Heliconius species contradicts such trend, such as that observed for $H$. ethilla near our study site (TSS, personal observation) and the current study. This fact may suggest a depletion of host and flower resources over a period of the year [30]. A similar pattern was found for the subtropical population of $H$. charitonia from North America, characterized by a seasonal peak from the end of the wet season and the onset of dry season [31]. The population of $H$. charitonia never disappeared completely and its seasonality was related to the availability of host-plant [31].

In the face of such results, a question remains: what happens to the population of $H$. s. apseudes between October and April, when no adult individual was detected? Diapause and host-plant dynamics may be important in explaining why we were unable to observe adult individuals after October. Fertilized females lay eggs during the cold and dry period (July-October) where climatic conditions are harsh and the availability and quality of host-plant is low. Evidence points to differences in quality between Heliconius host species (Passifloraceae) [32]. During the winter hostplants are almost totally defoliated and the tender meristem tissues are important for larval performance [33]. Such characteristics may favor a temporary delay in egg development until more favorable conditions are present, evidencing a potential diapause in the egg stage. As the temperature and humidity increases, host-plant availability increases as well, and hatchling larvae will feed on plants in full vegetative growth. Although diapause has never been documented before in Heliconius species [8], other butterfly species from the same locality pass through diapause stages including close relatives such as Actinote carycina (Nymphalidae) [34], or significant decreases in the developmental rate (e.g., Tegosa claudina) [35] during the dry period.

The Heliconius population studied may become extinct in the late dry season and may be recolonized by neighboring populations in late wet season (summer/early autumn) when conditions are favorable again. Individuals from a colonizing population mate and give rise to a new population between April and October. In another locality within its distribution, about $200 \mathrm{~km}$ from the target population, $H$. sara apseudes is a migrant [36]. On the other hand, tropical subspecies of $H$. sara, especially from the Amazon, are considered resident, with constant populations throughout the year without extinction and recolonization dynamics $[8,29]$.

One last hypothesis to explain the disappearance of the population lies on the formation of a pocket population within the forest in the same locality of this studied population between November and March. A pocket population is an elusive and small population with low detectability occurring in climatically stable localities into the forest [37]. When the availability of host-plant increases, the population explodes and colonizes other localities during the reproductive season (April to October). Pocket populations have never been described for Heliconius but have been documented in Ithomiinae butterflies [17], which inhabit areas with adverse conditions [38].

In this study, we showed seasonality for Heliconius sara apseudes population in the subtropical Southern Hemisphere. Our results demonstrate the need for new studies in neotropical butterflies to test the hypotheses here raised and further advance the knowledge on butterfly population dynamics and vital rates.

\section{Conflict of Interests}

The authors declare that there is no conflict of interests regarding the publication of this paper.

\section{Acknowledgments}

The authors thank Renato Rogner Ramos for helping and discussing ideas, Pablo Antiqueira for reviewing the final draft, and Emily Hamblen for English review. The Ecology Graduate Program of University of Campinas and CAPES provided financial support to Thadeu Sobral-Souza. Ronaldo Bastos Francini thanks Universidade Católica de Santos for logistic support.

\section{References}

[1] P. W. Price, R. F. Denno, M. D. Eubanks, D. L. Finke, and I. Kaplan, Insect Ecology: Behavior, Populations and Communities, Cambridge University Press, 2011.

[2] H. Wolda, "Insect seasonality: why?" Annual Review of Ecology and Systematics, vol. 19, pp. 1-18, 1988.

[3] M. Bigger, "Oscillations of tropical insect populations," Nature, vol. 259, no. 5540, pp. 207-209, 1976.

[4] H. Wolda, "Seasonal fluctuations in rainfall, food and abundance of tropical insects," The Journal of Animal Ecology, vol. 47, no. 2, pp. 369-381, 1978.

[5] H. Wolda, "Long-term' stability of tropical insect populations," Researches on Population Ecology, vol. 25, no. 3, pp. 112-126, 1983.

[6] P. R. Ehrlich and L. E. Gilbert, "Population structure and dynamics of the tropical butterfly Heliconius ethilla," Biotropica, vol. 5, no. 2, pp. 69-82, 1973.

[7] K. S. Brown Jr. and W. W. Benson, "Adaptive polymorphism associated with multiple mullerian mimicry in Heliconius numata," Biotropica, vol. 6, pp. 205-228, 1974.

[8] K. S. Brown Jr., "The biology of Heliconius and related genera," Annual Review of Entomology, vol. 26, pp. 427-456, 1981. 
[9] A. A. Berryman, "What causes population cycles of forest Lepidoptera?" Trends in Ecology and Evolution, vol. 11, no. 1, pp. 2832, 1996.

[10] M. D. Bowers, I. L. Brown, and D. Wheye, "Bird predation as a selective agent in a butterfly population," Evolution, vol. 39, no. 1, pp. 93-103, 1985.

[11] K. S. Brown Jr. and J. Vasconcellos-Neto, "Predation on aposematic ithomiine butterflies by tanagers (Pipraeidea melanonota)," Biotropica, vol. 8, pp. 136-141, 1976.

[12] B. Sillén-Tullberg, C. Wiklund, and T. Jarvi, "Aposematic coloration in adults and larvae of Lygaeus equestris and its bearing on mullerian mimicry: an experimental study on predation on living bugs by the great tit Parus major," Oikos, vol. 39, no. 2, pp. 131-136, 1982.

[13] R. R. Ramos and A. V. L. Freitas, "Population biology, wing color variation and ecological plasticity in Heliconius erato phyllis (Nymphalidae)," The Journal of the Lepidopterists' Society, vol. 53, pp. 11-21, 1999.

[14] D. A. Waller and L. E. Gilbert, "Roost recruitment and resource utilization: observations on a Heliconius charitonia L, roost in Mexico," The Journal of the Lepidopterists' Society, vol. 36, pp. 178-184, 1982.

[15] M. C. Peel, B. L. Finlayson, and T. A. McMahon, "Updated world map of the Köppen-Geiger climate classification," Hydrology and Earth System Sciences, vol. 11, no. 5, pp. 1633-1644, 2007.

[16] K. S. Brown Jr., Ecologia geográfica e evolução nas florestas neotropicais [Ph.D. thesis], Universidade Estadual de Campinas, Campinas, Brazil, 1979.

[17] P. J. DeVries, The Butterflies of Costa Rica and Their Natural History, Princeton University Press, Princeton, NJ, USA, 1987.

[18] M. G. Emsley, "A morphological study of image Heliconiinae (Lepidoptera: Nymphalidae) with a consideration of the evolutionary relationship within the group," Zoologica, vol. 48, pp. 85-130, 1973.

[19] K. S. Brown Jr. and O. H. Mielke, “The heliconians of Brazil (Lepidoptera: Nymphalidae). Part II. Introduction and general comments, with a supplementary revision of the tribe," Zoologica, vol. 57, pp. 1-40, 1972.

[20] G. Lamas, "Nymphalidae," in Atlas of Neotropical Lepidoptera, Vol 5A. Checklist, Part 4A Hesperioidea-Papilionoidea, G. Lamas, Ed., pp. 261-274, Association for Tropical Lepidoptera, Scientific Publisher, Gainesville, Fla, USA, 2004.

[21] M. Z. Cardoso, "New localities for Heliconius besckei Ménétriés and Heliconius sara (Fabricius) (Lepidoptera: Nymphalidae) in Bahia, Brazil," Neotropical Entomology, vol. 34, no. 6, pp. 10071008, 2005.

[22] W. W. Benson, K. S. Brown Jr., and L. E. Gilbert, "Coevolution of plants and herbivores: passion flower butterflies," Evolution, vol. 29, pp. 659-680, 1976.

[23] R. Pradel, "Utilization of capture-mark-recapture for the study of recruitment and population growth rate," Biometrics, vol. 52, no. 2, pp. 703-709, 1996.

[24] A. B. Franklin, "Exploring ecological relationships in survival and estimating rates of population change using program MARK," in Wildlife, Land, and People: Priorities for the 21st Century, pp. 350-356, The Wildlife Society, 2001.

[25] H. Akaike, "Information theory and an extension of the maximum likelihood principle," in Proceedings of the 2nd International Symposium on Information Theory, B. N. Petrov and F. Csaki, Eds., pp. 267-281, 1973.
[26] K. P. Burnham and D. R. Anderson, Model Selection and Multimodel Inference: A Practical Information-Theoretic Approach, Springer, New York, NY, USA, 2002.

[27] G. C. White and K. P. Burnham, "Program MARK: survival estimation from populations of marked animals," Bird Study, vol. 46, pp. S120-S139, 1999.

[28] P. R. Ehrlich, A. E. Launer, and D. D. Murphy, "Can sex ratio be defined or determined? The case of a population of checkerspot butterflies," American Naturalist, vol. 124, no. 4, pp. 527-539, 1984.

[29] M. I. M. Hernández and W. W. Benson, "Small-male advantage in the territorial tropical butterfly Heliconius sara (Nymphalidae): a paradoxical strategy?" Animal Behaviour, vol. 56, no. 3, pp. 533-540, 1998.

[30] R. R. Ramos, Seleção de planta hospedeira por Heliconius erato phyllis (Fabricius, 1775) (Lepidoptera, Nymphalidae, Heliconiini), no SE do Brasil. Uso, preferência e desempenho larval [M.S. dissertation], Universidade Estadual de Campinas, Campinas, Brazil, 2003.

[31] T. H. Fleming, D. Serrano, and J. Nassar, "Dynamics of a subtropical population of the zebra longwing butterfly Heliconius charithonia (Nymphalidae)," Florida Entomologist, vol. 88, no. 2, pp. 169-179, 2005.

[32] R. R. Ramos, D. Rodrigues, and A. V. L. Freitas, "Oviposition preference and larval performance in a Heliconius erato phyllis (Lepidoptera: Nymphalidae) population from southeastern Brazil: is there a positive relationship?" Journal of Natural History, vol. 46, no. 11-12, pp. 669-681, 2012.

[33] D. Rodrigues and G. R. P. Moreira, "Feeding preference of Heliconius erato (Lep.: Nymphalidae) in relation to leaf age and consequences for larval performance," Journal of the Lepidopterists' Society, vol. 53, no. 3, pp. 108-113, 2000.

[34] R. B. Francini, Ecologia das taxocenoses de Actinote (Lepidoptera: Nymphalidae) em Asteraeae (Angiosperma: Magnoliatae) no sudeste do Brasil: subsídios para conservação [Doctoral Thesis], Universidade Estadual de Campinas, Campinas, Brazil, 1992.

[35] A. V. L. Freitas, "Variacão morfológica, ciclo de vida e sistemática de Tegosa claudina (Eschscholtz) (Lepidoptera: Nymphalidae: Melitaeinae) no Estado de São Paulo, Brazil," Revista Brasileira de Entomologia, vol. 35, pp. 301-306, 1991.

[36] K. S. Brown Jr., "Borboletas da Serra do Japi: diversidade, habitats, recursos alimentares e variação temporal," in História natural da Serra do Japi: Ecologia e Preservação de uma Área Florestal no Sudeste do Brasil, L. P. C. Morellato, Ed., pp. 142-187, Editora da Unicamp, Campinas, Brazil, 1992.

[37] W. Haber, Evolutionary ecology of tropical mimetic butterflies (Lepidoptera: Ithomiinae) [Ph.D. thesis], University of Minnesota, Minneapolis, Minn, USA, 1978.

[38] C. E. G. Pinheiro, Í. M. Medri, and A. K. M. Salcedo, "Why do the ithomiines (Lepidoptera, Nymphalidae) aggregate? Notes on a butterfly pocket in central Brazil," Revista Brasileira de Entomologia, vol. 52, no. 4, pp. 610-614, 2008. 

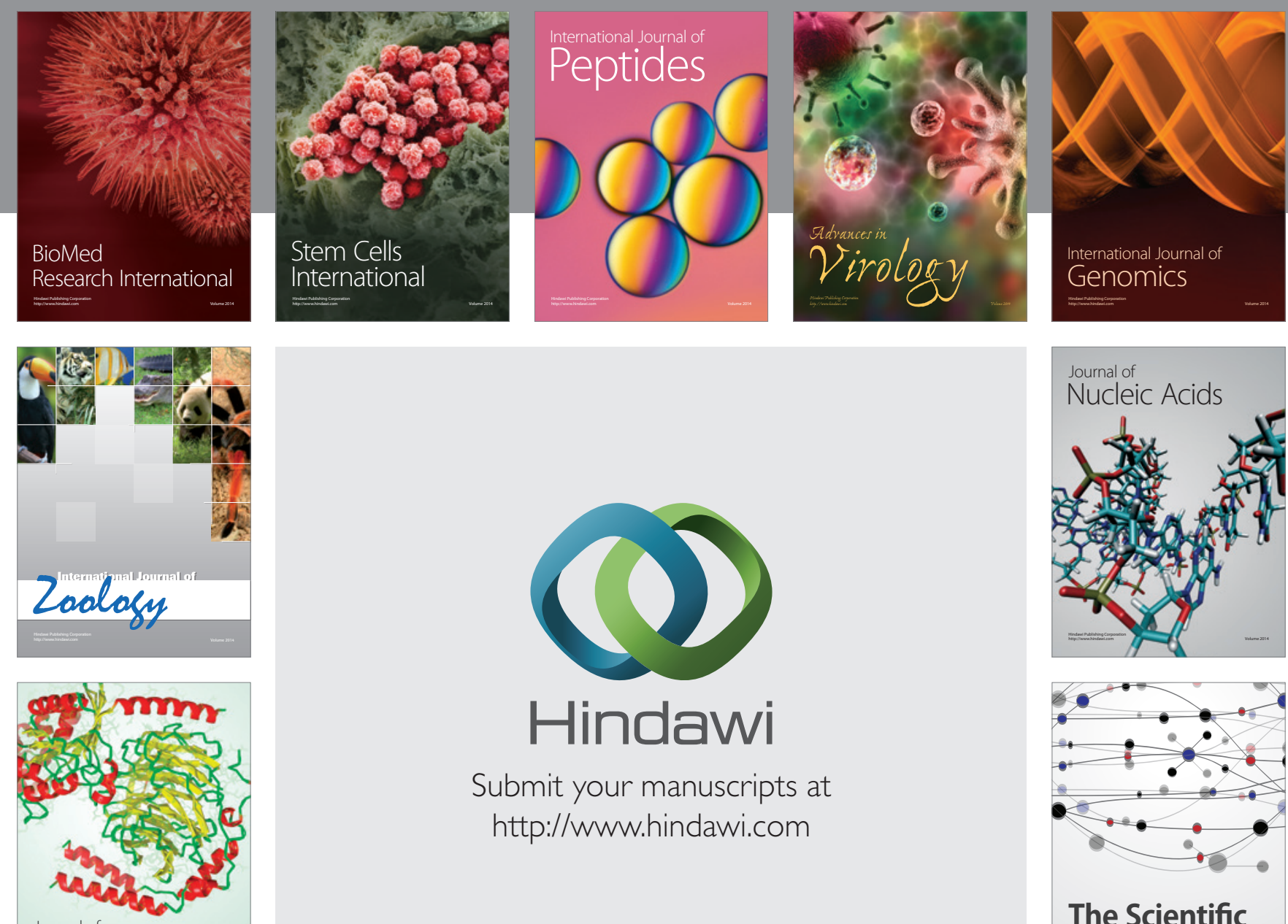

Submit your manuscripts at

http://www.hindawi.com

Journal of
Signal Transduction
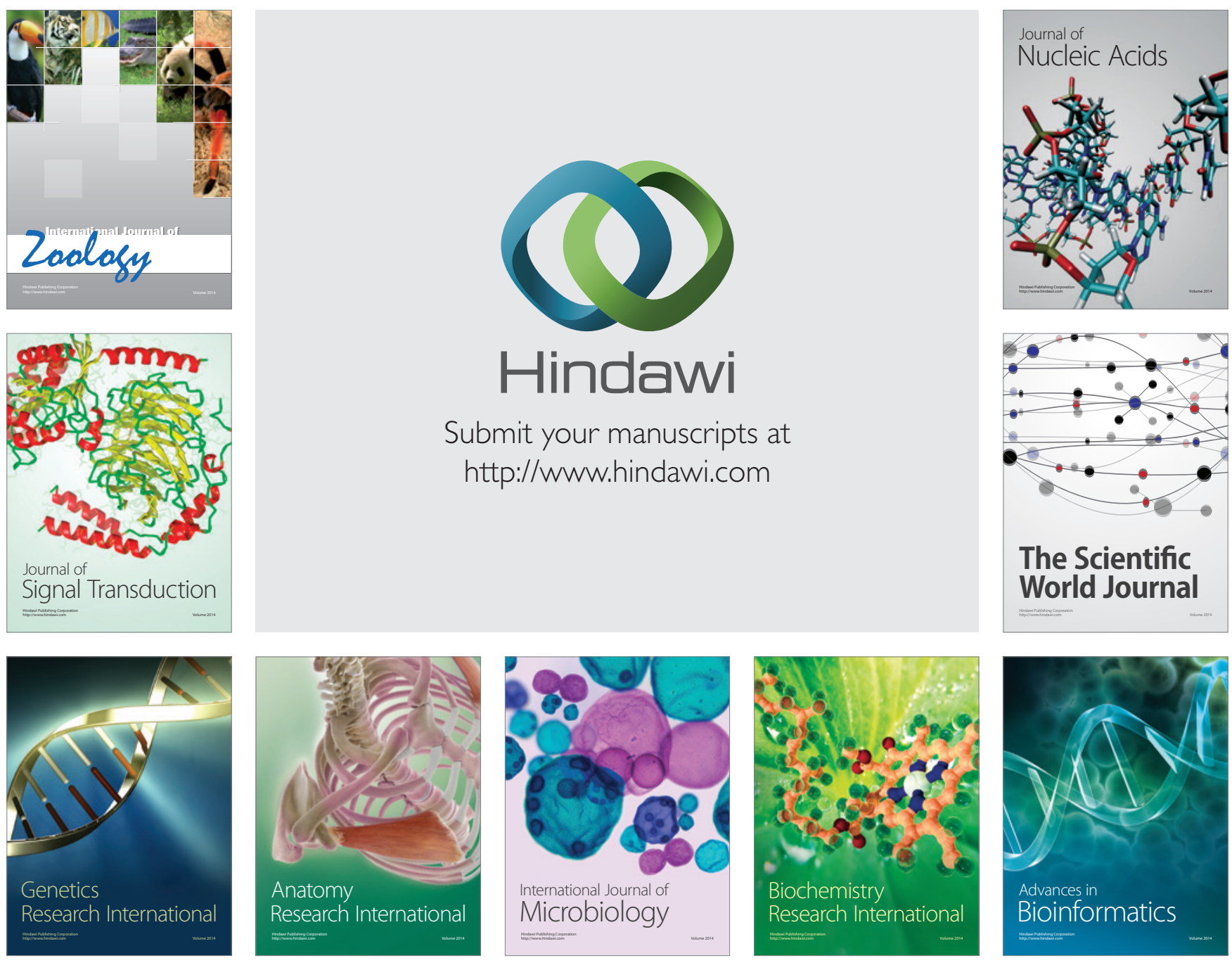

The Scientific World Journal
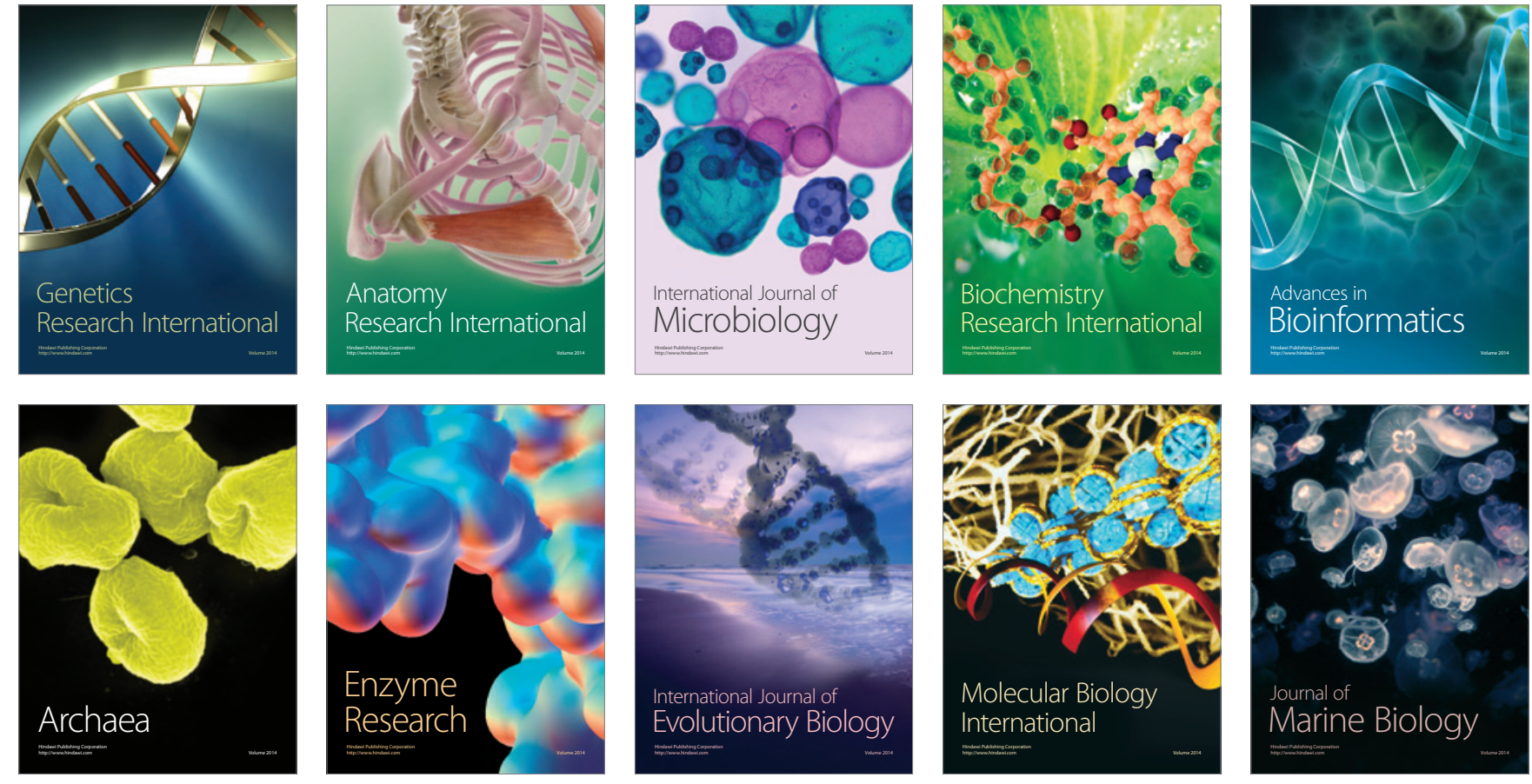